\title{
Comparison of asthmatic patients admitted to hospital from health districts experiencing high and low asthma mortality rates
}

\author{
P. Littlejohns, J. Hollowell, P. Hayward and S. Prance \\ Department of Public Health Sciences, St George's Hospital Medical School, Cranmer Terrace, London \\ SWI7 ORE, UK
}

Summary: Geographical variation in asthma mortality rates within the United Kingdom could be a reflection of variability in effectiveness of medical care services, or epidemiological variation. In order to ascertain whether differing hospital admission processes could contribute to this variation, asthmatic patients admitted from two districts, experiencing above and below average mortality rates were compared. The present study was part of a cohort study of 1,200 consecutive acute adult admissions in $1987 / 88$. In the main study, social data and information on referral were collected by interview for all patients. The admitting doctors' perception of the patient's severity was assessed on the basis of the severity of symptoms, and likelihood of morbidity or mortality if the patient was not admitted. Further information on asthmatic patients (treatment and physiological measurements) was retrieved from the notes.

Sixty-six asthmatic patients resident in Wandsworth (a district with high asthma mortality rates) were admitted to St George's Hospital or St James' Hospital (WW) and 31 patients resident in East Surrey (ES) (a district with low asthma mortality rates) were admitted to the East Surrey Hospital (ESH). Notes were obtained on $55(83 \%)$ and $27(87 \%)$ of patients in the two districts, respectively. WW received significantly more patients by self-referral: $68 \%$ of patients called an ambulance or came directly to casualty compared with $30 \%$ in ES (chi-squared $=13.7$, d.f. $=2, P=<0.001$ ). There was a tendency for more admissions to ESH to be taking oral steroids (chi-squared $=3.2$, d.f. $=1, P=0.07$ ). Patients admitted in WW tended to have more severe disease: $39(85 \%)$ of patients admitted to WW had peak expiratory flow less than $200 \mathrm{l} /$ minute on admission compared to $14(58 \%)$ in ES (chi-squared $=6$, d.f. $=1, P=0.01$ ). In WW the mean first recorded peak expiratory flow on admission was $1541 /$ minute compared to $172 \mathrm{l} /$ minute in ES; their mean peak flow on discharge was $318 \mathrm{l} /$ minute compared with $377 \mathrm{l} /$ minute in ES. Twenty-one (38\%) of admissions in WW were considered to be very urgent by the admitting hospital doctor compared to four (15\%) in ESH (chi-squared $=4.67$, d.f. $=1, P=0.03$ ).

This opportunistic study found that, in an area experiencing high mortality rates, more patients with severe disease were admitted to hospital compared to a low mortality area. This does not appear to be due to differing hospital practices but rather to increased levels of morbidity in the community. As patients with more severe asthma are at a greater risk of dying, these findings reinforce the need to standardize asthma treatment in the community.

\section{Introduction}

There is considerable geographical variation in death rates from asthma within the United Kingdom. Some health districts have a standardized mortality ratio for asthma up to 14 times that of others. ${ }^{1}$ These differences could be a reflection of variability in effectiveness of medical care services ${ }^{2}$ or epidemiological variation. ${ }^{3}$

Correspondence: P. Littlejohns, M.D., B.Sc., M.F.P.H.M., M.R.C.G.P.

Accepted: 12 August 1993
Confidential mortality enquiries into asthma deaths and case control studies ${ }^{4-11}$ have reported that preventable factors were present in over three-quarters of patients investigated. These included poor patient education, $, 5,8$ underestimation of severity of attacks, ${ }^{4,8}$ and inadequate assessment, monitoring and treatment of attacks. ${ }^{5,7,8}$ Investigation of non-fatal asthma attacks leading to admission to hospital have demonstrated that there is often inadequate treatment prior to hospital admission and variation in management after admission. ${ }^{12,13}$ 
The majority of asthmatics are managed in the community by their general practitioner (GP) with only a minority admitted to hospital ${ }^{14}$ Referring the appropriate patient to hospital is likely to be an important step in lowering mortality due to asthma. This decision depends on the severity of the asthma ${ }^{15,16}$ the characteristics of the patient and his/her environment, ${ }^{17}$ the general practitioner, ${ }^{18}$ and the availability of hospital facilities and admission policies. ${ }^{19,20}$

In the winter of $1987 / 88$, two cohorts of acute adult admissions to hospital from two health districts in South West Thames Health Region were investigated as part of a larger study of the effect of social factors on acute hospital use. As one of these districts had one of the highest asthma mortality rates in the country and the other had below average mortality rates, we took the opportunity to investigate in more detail patients admitted with a diagnosis of asthma. The objective was to ascertain whether the hospital admission processes for asthmatics differed between districts and, if so, whether the finding could contribute to our understanding as to why districts have different death rates due to asthma.

\section{Methods}

The present study of acute asthma admissions was part of a larger investigation of two cohorts of 1,200 consecutive acute adult admissions in the winter of $1987 / 88$ to general medicine, general surgery and geriatrics in five hospitals in two districts in South West Thames Region: Wandsworth Health Authority (WW) and East Surrey Health Authority (ES). Characteristics of the two districts are summarized in Table I.

In the main study, social data and information about GP contact and referral into hospital were collected by means of an interviewer-administered questionnaire; diagnoses and length of stay were extracted from the Körner Hospital Episode System; and information on severity and the need for admission was recorded by the admitting doctor at the time of admission using a structured assessment developed for the study.

Table I Characteristics of study districts

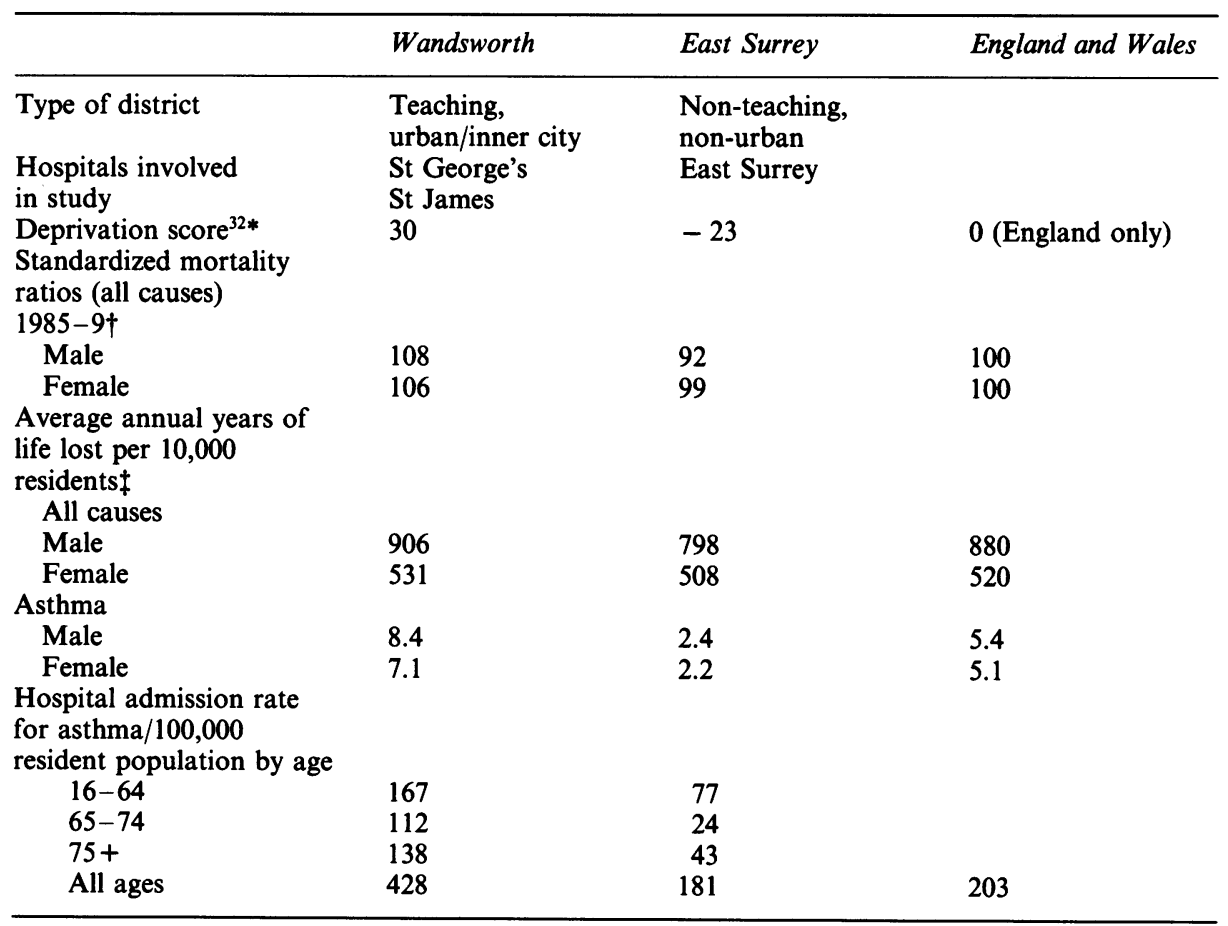

*The score is a weighted average of the following census variables: elderly living alone, children under 5 years of age, one parent families, unskilled socio-economic groups, the unemployed, overcrowding, change of address within one year, household headed by a person born in the New Commonwealth or Pakistan. The higher the score, the greater the deprivation. $†$ The standarized mortality ratio is the ratio of observed to expected deaths in an area for 1985-89 multiplied by 100. $¥$ Years of life lost up to age 75 per 10,000 residents for all causes of death and deaths due to asthma. 
Table II Comparison of management of patients admitted in the two districts

\begin{tabular}{|c|c|c|}
\hline & $\begin{array}{l}\text { Wandsworth } \\
(\mathrm{n}=55)\end{array}$ & $\begin{array}{l}\text { East Surrey } \\
(\mathrm{n}=27)\end{array}$ \\
\hline \multicolumn{3}{|l|}{$\begin{array}{l}\text { Drug therapy prior } \\
\text { to admission }\end{array}$} \\
\hline Inhaled sympathomimetics & $51(93 \%)$ & $24(89 \%)$ \\
\hline Cholinergic & $7(13 \%)$ & $8(30 \%)$ \\
\hline Xanthine derivative & $17(31 \%)$ & $13(48 \%)$ \\
\hline Antibiotic & $5(9 \%)$ & $8(30 \%)$ \\
\hline Oral steroids $\dagger$ & $12(22 \%)$ & $11(41 \%)$ \\
\hline Inhaled steroids & $18(33 \%)$ & $5(19 \%)$ \\
\hline $\begin{array}{l}\text { Seen by GP in previous } \\
24 \text { hours }\end{array}$ & $\begin{array}{l}25(52 \%) \\
\left(n=48^{*}\right)\end{array}$ & $\begin{array}{l}14(56 \%) \\
\left(n=25^{*}\right)\end{array}$ \\
\hline \multicolumn{3}{|l|}{ Method of admission $\ddagger$} \\
\hline $\begin{array}{l}\text { Came direct to casualty } \\
\text { or called ambulance }\end{array}$ & $36(68 \%)$ & $8(30 \%)$ \\
\hline Sent by GP & $11(21 \%)$ & $7(26 \%)$ \\
\hline Told to call ambulance by GP & $\begin{array}{c}6(11 \%) \\
\left(n=53^{*}\right)\end{array}$ & $\begin{array}{l}12(44 \%) \\
\left(n=27^{*}\right)\end{array}$ \\
\hline $\begin{array}{l}\text { Admission under respiratory } \\
\text { physician }\end{array}$ & $21(38 \%)$ & $12(44 \%)$ \\
\hline $\begin{array}{l}\text { Social factors considered unimportant } \\
\text { in the decision to admit }\end{array}$ & $53(96 \%)$ & $23(85 \%)$ \\
\hline \multicolumn{3}{|l|}{ Previous admissions } \\
\hline No previous admissions & $3(5 \%)$ & $3(12 \%)$ \\
\hline $\begin{array}{l}\text { Admitted over } 12 \text { months } \\
\text { prior to present admission }\end{array}$ & $28(48 \%)$ & $9(38 \%)$ \\
\hline Admitted in previous & $27(47 \%)$ & $12(50 \%)$ \\
\hline 12 months & $\left(n=47^{*}\right)$ & $\left(n=20^{*}\right)$ \\
\hline \multicolumn{3}{|l|}{ Length of stay (days) } \\
\hline Mean & 5.4 (s.d. 3.5) & 4.5 (s.d. 2.7) \\
\hline Median & 5 & 4 \\
\hline
\end{tabular}

*Response to this question not available for some patients; tchisquared $=3.21$, d.f. $=1, P=0.07 ;$ chi-squared $=13.7$, d.f. $=1, P=0.001$.

The admission assessment focused on two dimensions of severity: urgency, expressed in terms of the doctor's opinion of the likelihood of serious morbidity or mortality if the patient was not admitted; and severity of presenting symptoms/ signs. The questions asked are presented in Tables III and IV. Because of the small number of asthmatics admitted, the answers were dichotomized into very urgent and urgent; very severe and severe. The admitting doctor also assessed the importance of social factors/the patient's home circumstances in the decision to admit and specified possible alternatives to admission.

For the present study, patients admitted with a diagnosis of asthma were identified using the diagnostic codes recorded in the hospital episode system. Their notes were retrieved and diagnosis confirmed. Non-residents of the two districts were excluded. To ensure that all patients likely to be suffering with asthma would be included, patients with a diagnosis of chronic obstructive airways disease were also identified and assessed. This paper only deals with patients given a diagnosis of asthma although, when patients with the diagnosis of chronic obstructive airways disease ( 90 patients in all) were analysed, the results and conclusions were the same.

Physiological indices, treatment information prior to admission and after admission, and investigations, were ascertained from the notes by a trained medical student (SP). Data were obtained relating to the whole stay of the patient, that is, in casualty, on the ward and at discharge. Case-note data were merged with data from the main study. It was subsequently found that, in accordance with similar studies, ${ }^{21,22}$ data on physiological status were only recorded systematically in the notes for pulse and peak expiratory flow rate. For example, 
Table III Comparison of indices of severity on admission to hospital

\begin{tabular}{|c|c|c|c|}
\hline & $\begin{array}{l}\text { Wandsworth } \\
(\mathrm{n}=55)\end{array}$ & $\begin{array}{l}\text { East Surrey } \\
(\mathrm{n}=27)\end{array}$ & Significance $(\mathrm{P})$ \\
\hline $\begin{array}{l}\text { Duration of symptoms } \\
\text { Less than a week } \\
\text { More than a week }\end{array}$ & $\begin{array}{r}45(85 \%) \\
8(15 \%)\end{array}$ & $\begin{array}{r}18(67 \%) \\
9(33 \%)\end{array}$ & 0.06 \\
\hline $\begin{array}{l}\text { Pulse rate } \\
\text { (mean rate per minute) }\end{array}$ & 103 (s.d. 17.9) & 105 (s.d. 25.5) & 0.1 \\
\hline $\begin{array}{l}\text { Peak flow } \\
\text { Peak flow (admission) } \\
\text { (mean litres per minute) }\end{array}$ & $\begin{array}{l}154 \text { (s.d. 72.3) } \\
\left(n=46^{*}\right)\end{array}$ & $\begin{array}{l}172 \text { (s.d. 78.8) } \\
\left(n=24^{*}\right)\end{array}$ & 0.6 \\
\hline Peak flow (discharge) & $\begin{array}{l}318 \text { (s.d. } 110) \\
\left(n=47^{*}\right)\end{array}$ & $\begin{array}{l}377 \text { (s.d. 108) } \\
\left(n=27^{*}\right)\end{array}$ & $<0.05$ \\
\hline $\begin{array}{l}\text { Peak flow difference } \\
\text { (admission peak flow as } \\
\% \text { of discharge peak flow) }\end{array}$ & $\begin{array}{l}49 \% \text { (s.d. } 24) \\
\left(n=39^{*}\right)\end{array}$ & $\begin{array}{l}45 \% \text { (s.d. } 18) \\
\left(n=24^{*}\right)\end{array}$ & 0.5 \\
\hline $\begin{array}{l}\text { Perception of severity } \dagger \\
\text { Very urgent } \\
\text { Urgent } \\
\text { Very severe } \\
\text { Severe }\end{array}$ & $\begin{array}{l}21(38 \%) \\
34(62 \%) \\
11(20 \%) \\
44(80 \%)\end{array}$ & $\begin{array}{c}4(15 \%) \\
23(85 \%) \\
2(7 \%) \\
25(93 \%)\end{array}$ & 0.03 \\
\hline
\end{tabular}

*Data not available for some patients. †Question on urgency of admission/immediate prognosis without admission: considering the patient's clinical condition on admission, how likely was the provisional admission diagnosis to lead to death, increase morbidity or other serious consequences if not admitted? Very likely (category 1), likely (category 2), unlikely (category 3), not at all likely (category 4 ). Very urgent $=$ category one, urgent $=$ category two and three. There were no patients in category four.

Question on severity of presenting symptoms/signs: How severe were the patient's symptoms at time of admission? Category 1 - very ill, severe disturbance of vital functions; for example, semi/unconscious, shock, respiratory failure. Category 2 - less than above, but patient immobilized. Category 3 - not immobilized but some restriction of normal activities. Category 4 asymptomatic or minor symptoms, transient symptoms experienced before hospitalization, abnormal signs on examination. Very severe $=$ category 1 , severe $=$ category two and three. No patients were in category 4.

only $33 \%$ of patients had pulsus paradoxus recorded and $52 \%$ had blood gases recorded. Virtually no patients had height or predicted normal peak expiratory flow rates recorded. Therefore only pulse and peak expiratory flow rate were used in subsequent analyses. Peak expiratory flow rate was classified as first recorded during admission (litres per minute), last recorded during current admission and the first expressed as a percentage of the last. This last measure was an indicator of improvement during the admission.

Data were analysed by the PC version of the Statistical Package for Social Sciences. Physiological indices were classified into severe and non-severe according to the British Thoracic Society (BTS) guidelines. ${ }^{23}$ The distribution of physiological indices in each perceived severity and urgency category was assessed by comparison of means (when variable was normally distributed) or by proportions of severe cases as classified by the BTS guidelines. Analysis of variance was used to compare means and chi-squared statistic for the proportions. Social class was classified according to the registrar general's classification.

\section{Results}

Sixty-six asthmatic patients resident in Wandsworth were admitted to St George's Hospital or St James' Hospital in Wandsworth (WW), and 31 patients resident in East Surrey were admitted to the East Surrey Hospital (ESH) from the East Surrey area (ES). Notes were obtained on $55(83 \%)$ and $27(87 \%)$ of patients in the two districts, respectively. The mean age of patients admitted in WW was 39.1 years (s.d. 17.4) and 32.9 (s.d. 15.4) in ES. Twenty $(36 \%)$ of the Wandsworth admissions and five $(19 \%)$ of the East Surrey admissions were male. Ten $(37 \%)$ admissions in ES and $19(35 \%)$ of the WW admissions were current smokers.

There was little difference in the social class 
Table IV The relationship between perceived severity* of asthma by admitting doctor and physiological indices and subsequent length of stay in both hospitals

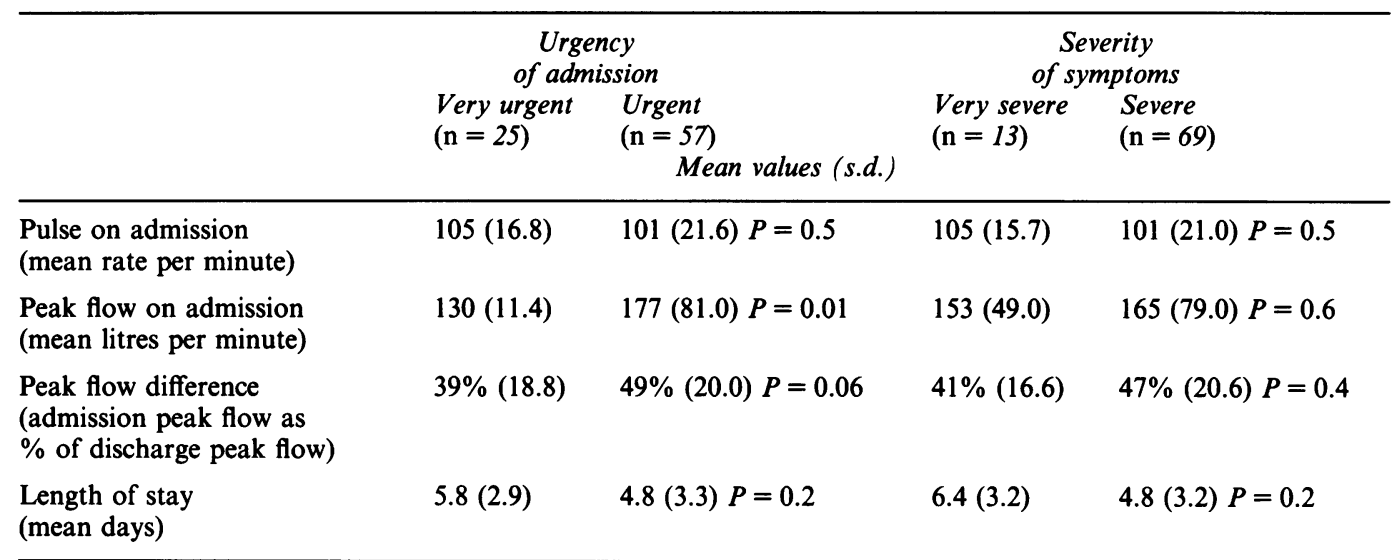

*See Table III for definitions.

distribution of admissions between the two districts, $30(55 \%)$ admissions in WW were from non-manual social classes, $11(20 \%)$ from manual, and $14(25 \%)$ were economically inactive. In ES, 17 $(62 \%)$ were from the non-manual social classes, four $(14 \%)$ from manual and six $(24 \%)$ were economically inactive.

\section{Management of patients (Table II)}

WW received significantly more patients by selfreferral: $68 \%$ of patients called an ambulance or came directly to casualty compared with $30 \%$ in ES (chi-squared $=13.7$, d.f. $=2, P=<0.001$ ). There was a tendency for more admissions to ESH to be taking oral steroids (chi-squared $=3.2$, d.f. $=1$, $P=0.07)$.

\section{Severity of asthma (Table III)}

Patients admitted in WW tended to have more severe disease. Thirty-nine $(85 \%)$ of patients admitted to WW had peak expiratory flow less than $2001 /$ minute $^{23}$ on admission compared to $14(58 \%)$ in ES (chi-squared $=6$, d.f. $=1, P=0.01$ ). In WW the mean first recorded peak expiratory flow on admission was $154 \mathrm{l} /$ minute (median $150 \mathrm{l} /$ minute) compared to $172 \mathrm{l} /$ minute (median $190 \mathrm{l} /$ minute) in ES; their mean peak flow on discharge was 3181 / minute (median 320 l/minute) compared with 377 1/minute (median $370 \mathrm{l} /$ minute) in ES. Twentyone $(38 \%)$ ) of admissions in WW were considered to be very urgent by the admitting hospital doctor compared to four $(15 \%)$ in ESH (chi-squared = 4.67 , d.f. $=1, P=0.03$ ).

The admitting doctors perception of urgency related more closely to the physiological indices of severity than their perception of the severity of symptoms (Table IV). Both predicted subsequent length of stay.

\section{Discussion}

High mortality due to asthma is likely to be due to a combination of epidemiological, medical care and social factors. The prevalence and severity of disease in the community are clearly important, but medical care factors such as the accessibility, level of provision, organization and appropriateness of primary and secondary care may be equally relevant; and social factors may affect both of these areas by modifying the level of disease and/or the process of medical care.

There are no studies in which all this information on asthmatics has been collected. This means that the relative importance of epidemiological versus health service factors in determining asthma mortality is ill understood. The study presented here has enabled us to gain insight into the treatment, severity, social characteristics and referral behaviour of patients in two districts with different mortality rates for asthma.

Patients admitted to hospital from a district with a high death rate from asthma were more severe in terms of their physiological status and the admitting doctor's assessment, compared to those admitted from a low mortality area. This is unlikely to be due to differing diagnostic practices alone as the same pattern was seen for patients diagnosed as having chronic obstructive airways disease. 
One reason could be that there were different thresholds for hospital admission due to greater pressure on beds in Wandsworth. Alternatively general practitioners in Wandsworth could have more access to community facilities (for example, nebulizers, asthma nurses) and prefer to treat asthmatics at home leading to more severe disease when patients are finally admitted. There are a number of results, however, that mitigate against these explanations. A higher admission threshold combined with a greater propensity to treat patients at home in Wandsworth would mean that patients would be expected to have had symptoms for a longer period of time prior to admission compared with patients admitted in East Surrey. In fact the opposite was the case with $85 \%$ of Wandsworth patients having symptoms for less than a week compared with $67 \%$ in East Surrey $(P=0.06)$. Also individual patients would have been expected to have been admitted less frequently in the past, and Wandsworth would be expected to have low asthma admission rates, neither of which was the case. Wandsworth's overall asthma admission rate, for example, is one of the highest in England, exceeded only in Sunderland, Bradford, Dewsbury, Newham and Brighton, while East Surrey residents have an asthma admission rate close to the median for England. ${ }^{24}$ In addition, there is no evidence to suggest that Wandsworth general practitioners have greater access to community support for asthmatic patients. In fact, the reverse is likely to be the case. ${ }^{25}$

The difference in severity of asthmatics admitted between the two districts raises the question of appropriateness of admission. Are doctors in Wandsworth turning away or not being presented with asthmatics who should be admitted, or are doctors in East Surrey admitting patients who could be managed at home? A limitation of this study is that information is only available on those patients admitted. However, some clues are provided by differences in the method of admission. Wandsworth, in common with other inner-city districts, admitted significantly more patients following self-referral: $68 \%$ of patients called an ambulance or came directly to casualty. In contrast, $66 \%$ of East Surrey patients admitted had been referred by their general practitioner. It could be that hospital doctors are more reluctant to send home patients who have caused sufficient concern to their GP for him/her to arrange assessment.

Also it may be that because East Surrey patients were likely to be taking oral steroids there was concern that, despite taking appropriate therapy ${ }^{23}$ they were still ill. Similar proportions of patients were admitted under specialist respiratory teams in both hospitals, although that does not necessarily guarantee the individual admitting doctors' ability to assess acute asthma.
Medical staffing factors might also affect the level of inappropriate admissions. For example, as a teaching district, there may be greater involvement of more senior or experienced doctors in the decision to admit in Wandsworth, although we have no evidence of this.

Poor social circumstances did not appear to be involved directly in the doctor's assessment of the need to admit, although they might have contributed to the severity of asthma and therefore affected the chance of admission indirectly. If they had played a role in the decision to admit, it would have been expected to affect Wandsworth more, as a more deprived area and would have tended to lead to a decrease in the severity of asthmatics admitted.

When all these possibilities are taken into account the findings suggest that the increased severity of patients admitted in Wandsworth represents a greater burden of disease in the community. This could be due to greater numbers of asthma patients or similar numbers of asthmatics with more severe disease. Recent studies suggest that geographical variation in the prevalence of asthma in adults is not great in the UK. ${ }^{26}$ This means that variation in asthma severity may be important. This could reflect differences in exposure to exacerbating factors, for example, environmental pollutants ${ }^{27}$ or inadequate primary care treatment. ${ }^{28}$ Social class has been shown to effect morbidity ${ }^{29}$ and mortality ${ }^{30}$ and would have been predicted to be a cause of the increased disease load in Wandsworth. It was interesting therefore to find little difference in the social distribution between the hospital admissions. However, this may reflect diagnostic preference. It has been demonstrated that wheezing patients from the higher social classes are more likely to be labelled as asthmatic than the lower social classes, who are given a label of chronic bronchitis. ${ }^{31}$ Therefore patients of lower social class admitted would be labelled as suffering from chronic obstructive airway disease. In this study we were also able to assess patients with a label of chronic obstructive airways disease. There were the same differences in disease severity between the two hospitals as in the asthmatic patients. Another explanation could be that patients from higher social class were more likely to maximize the use of medical facilities, although this would not explain the differences in severity between districts. Another major asthma exacerbating factor is smoking but again a similar proportion smoked in both hospitals.

It may be that differences in management prior to hospitalization contributed to increased morbidity. If oral steroids are used as an indicator of appropriate treatment, then more patients admitted to East Surrey were being treated appropriately. Interestingly there was little difference in the 
proportions seeing their general practitioner in the 24 hours prior to admission, so accessibility of doctor does not appear to be an issue. These findings suggest that differing management regimes in primary care may be important in affecting the severity of asthma and hence the chance of admission.

In summary this opportunistic study found that, in an area experiencing high mortality rates, more patients with severe disease were admitted to hospital compared to a low mortality area. This does not appear to be due to differing hospital practices but rather to increased levels of morbidity in the community. While underlying variation in prevalence cannot be ruled out, this study suggests that variation in asthma severity may be an important contributing factor. There was no variation in at least one exacerbating factor, smoking, but there was evidence that management differed prior to hospitalization. This could have contributed to the increased severity of asthma in one district. As patients with more severe asthma are at greater risk of dying these findings reinforce the need to standardize asthma treatment in the community. In order to investigate further the geographical variation in asthma mortality, a multicentre controlled study should be instigated. This would need to look prospectively at severe asthmatics from heatlh districts with different asthma mortality experience.

\section{Acknowledgement}

We would like to thank Professor Ross Anderson for his advice throughout the study and Dr Derek Cook for his comments on the statistical analysis.

\section{References}

1. Charlton, J.R.H., Hartley, R.M., Silver, R. \& Holland, W.W. Geographical variation in mortality amenable to medical intervention in England and Wales. Lancet 1983, i: 691-696.

2. Mackenbach, J.P., Bouvier-Colle, M.H. \& Jougla, E. 'Avoidable' mortality and health services: a review of aggregate data studies. J Epidemiol Community Health 1990, 44: $106-111$.

3. Burney, P.G.J., Papacosta, A.O., Withey, C.H., Colley, J.R.T. \& Holland, W.W. Hospital admission rates and the prevalence of asthma symptoms in 20 local authority districts. Thorax 1991, 46: 574-579.

4. Frazier, P.M., Speizer, F.E.L., Waters, S.D.M., Doll, R. \& Mann, N.M. The circumstances preceding death from asthma in young people in 1968 to 1969 . Br J Dis Chest 1971, 65: 71-84.

5. MacDonald, J.B., Macdonald, E.T., Seaton, A. \& Williams, D.A. Asthma deaths in Cardiff 1963-74: 53 deaths in hospital. Br Med J 1976, i: 721-723.

6. MacDonald, J.B., Seaton, A. \& Williams, D.A. Asthma deaths in Cardiff 1963-74: 90 deaths outside hospital. $\mathrm{Br}$ Med J 1976, i: 1493-1495.

7. Omerod, L.P. \& Stableforth, D.E. Asthma mortality in Birmingham 1975-7: 53 deaths. Br Med J 1980, 280: 987-990.

8. British Thoracic Association. Death from asthma in two regions in England. $\mathrm{Br}$ Med J 1982, 285: 1251-1255.

9. Cochrane, G.M. \& Clark, T.J.H. A survey of asthma mortality in patients between the ages of 35 and 64 in the Greater London Hospitals in 1971. Thorax 1975, 30: 300-305.

10. Rea, H.R., Scragg, R., Jackson, R., Beaglehole, R., Fenwick, J. \& Sutherland, D.C. A case-control study of deaths from asthma. Thorax 1986, 41: 833-839.

11. Eason, J. \& Markowe, H.L.J. Controlled investigation of deaths from asthma in hospital in the North East Thames Region. Br Med J 1987, 294: 1255-1258.

12. Bucknall, C.E., Robertson, C., Moran, F. \& Stevenson, R.D. Differences in hospital asthma management. Lancet 1988, i: $748-750$.

13. Bucknall, C.E., Robertson, C., Moran, F. \& Stevenson, R.D. Managements of asthma in hospital: a prospective audit. $\mathrm{Br}$ Med J 1988, 296: 1637-1639.
14. Office of Populations Censuses and Surveys, Royal College of General Practitioners and Department of Health and Social Security. Morbidity Statistics from General Practice. Third National Study 1981-82. HMSO, London, 1986 (series mb 5 no. 1).

15. Littlejohns, P., Ebrahim, S. \& Anderson, H.R. Treatment of adult asthma; is the diagnosis relevant? Thorax 1989, 44: 792-802.

16. Bolliger, C.T., Fouries, P.R., Kotze, D. \& Joubert, J.R. Relation of measures of asthma severity and response to treatment to outcome in acute severe asthma. Thorax 1992, 47: $943-947$

17. Anderson, H.R., Freeling, P. \& Patel, S.P. Decision-making in acute asthma. $J R$ Coll Gen Pract 1983, 33: 105-108.

18. Crombie, D.L. \& Fleming, D.M. General practitioner referrals to hospital, the financial implications of variability. Health Trends 1988, 20: 53-56.

19. Morgan, M., Mays, N. \& Holland, W.W. Can hospital use be a measure of need for health care. $J$ Epidemiol Community Health 1987, 41: 269-274.

20. Department of Health. Public Health Common Data Set 1990. Compiled by the Institute of Public Health, University of Surrey. Crown copyright.

21. Bell, D., Layton, A.J. \& Gabbay, J. Use of a guideline questionnaire to audit hospital case of acute asthma. $\mathrm{Br} \mathrm{Med}$ $J$ 1991, 302: 1440-1443.

22. Lipworth, B.J., Jackson, C.M., Ziyaie, D., Winter, J.H., Dhillon, P.D. \& Clark, R.A. An audit of acute asthma admissions to a respiratory unit. Health Bull 1992, 50: 389-398.

23. Brewis, G. Guidelines for the management of asthma in adults. ii. Acute severe asthma. Br Med J 1990, 301: 797-800.

24. Department of Health Performance Indicators 1990. HMSO, London.

25. Primary Health Care in Inner London: Report of a Study Group. Commissioned by the London Health Planning Consortium, 1981

26. Strachan, D.P., Golding, J. \& Anderson, H.R. Regional variations in wheezing illness in British children: effect of migration during early childhood. J Epidemiol Community Health 1990, 44: 231 -236. 
27. Department of Health Advisory Group on the Medical Aspects of Air Pollution Episodes. London, HMSO, 1991.

28. Jones, K.P., Charlton, I.H., Middleton, M., Preece, W.J. \& Hill, A.P. Targeting asthma in general practice using a morbidity index. Br Med J 1992, 304: 1353-1356.

29. Littlejohns, P. \& MacDonald, L. The relationship between severe asthma and social class. Respir Med 1993, 87: 139-143.
30. Office of Populations Censuses and Surveys. 1979-80, 1982-83. Occupational Mortality Decennial Supplement. Part 1 commentary. Series D6 no 6. HMSO, London, 1986.

31. Littlejohns, P., Ebrahim, S. \& Andeson, H.R. The prevalence and diagnosis of chronic respiratory symptoms in adult. $\mathrm{Br}$ Med J 1989, 298: 1556-1560.

32. Jarman, B. Underprivileged areas: validation and distribution of scores. Br Med J 1984, 289: 1587-1592. 